ORIGINAL ARTICLE

\title{
The effects of $5 \times 5$ exercises on a quality of life of university students, who use smartphones during long periods
}

\author{
Aysenur Tuncer $^{\mathrm{ABDE}}$, Tuba Maden ${ }^{\mathrm{BC}}$, Tugba Badat ${ }^{\mathrm{B}}$, Deniz Kocamaz ${ }^{\mathrm{CD}}$ \\ Department of Physiotherapy and Rehabilitation, Hasan Kalyoncu University, Gaziantep, Turkey
}

\author{
Authors' Contribution: A- Study design; B- Data collection; C- Statistical analysis; D- Manuscript Preparation; \\ E-Funds Collection.
}

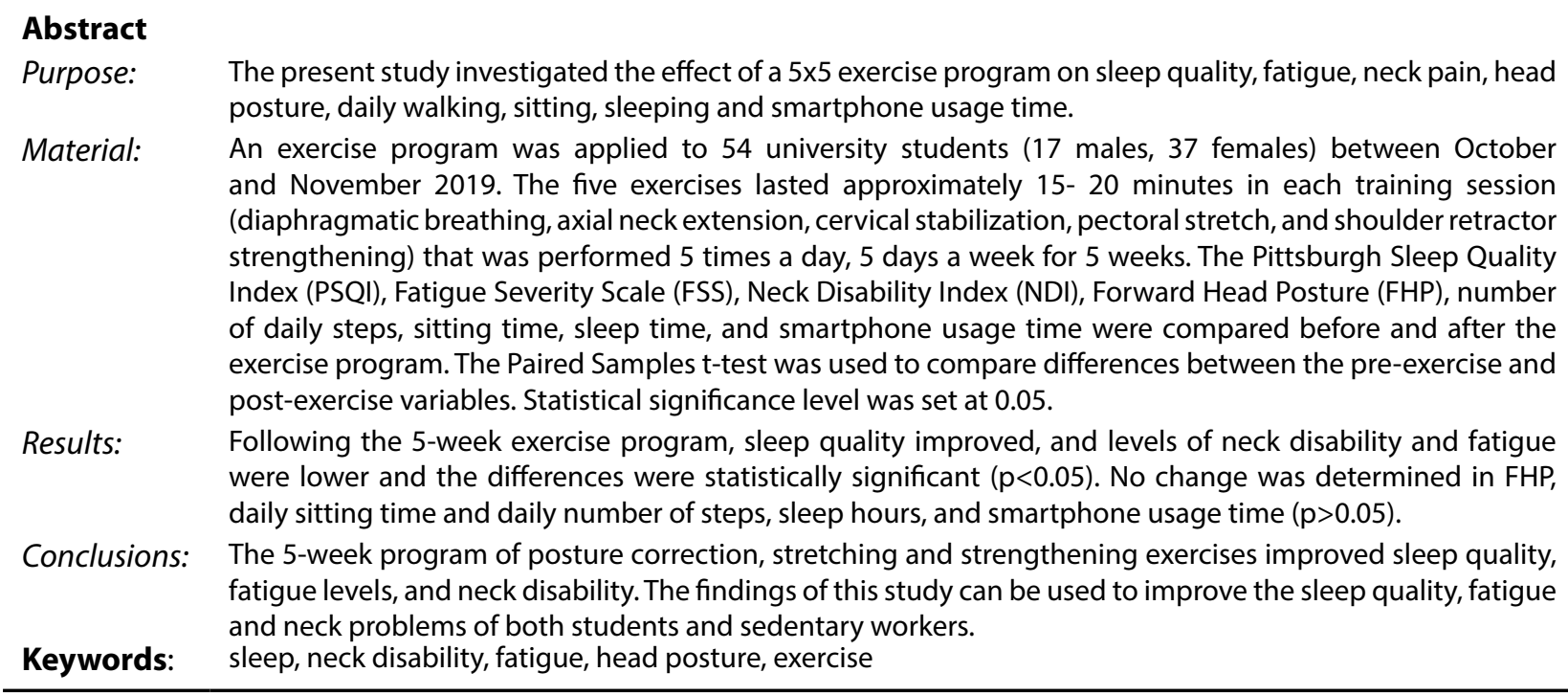

\section{Introduction}

The opportunities provided by current technology have significantly facilitated daily life, and the rapid developments in global technology are followed with great interest by young people. The use of technological devices has increased as they allow the user to access the internet and social media at any time and place, and to easily create content and access different content. However, increased usage of technological devices can create addiction [1-3]. These addictions, which are counted as a type of behavioural addiction have been defined as technology addiction $[4,5]$. Technology addiction leads to psychiatric, behavioural and sociological problems, and has a negative effect in particular on the physical movement of young people $[6,7]$. In studies of university students, long periods of sitting, being able to undertake daily work on the internet, and low levels of physical activity and habitual exercise have been determined as the primary factors in the emergence of neck, back and upper extremity problems, and especially headaches [8-10].

During long periods of use of computers and smartphones, there is a forced position change in body posture with the head and neck placed in forward flexion position (FHP). Repeated movements of the neck and upper extremities in this forced posture have been determined to cause the formation of musculoskeletal system symptoms $[9,10]$. The FHP has been reported to be seen at the rate of $60 \%$ in individuals with neck

(c) Aysenur Tuncer, Tuba Maden, Tugba Badat, Deniz Kocamaz, 2020 doi:10.15561/20755279.2020.0503 problems and it has been emphasised that the tendency for FHP is increased in computer or smartphone users who remain seated for more than 2 hours a day [11]. This postural stress formed in the neck associated with FHP leads to musculoskeletal system problems such as pain and restriction, and these problems are seen not only in the neck but also in other regions of the body. Moreover, the duration of device use has been reported to be associated with sleep irregularities, reduced sleep quality, diurnal tiredness, headache, reduced levels of concentration, and increased levels of stress $[12,13]$.

There have been important changes in education systems throughout the world, especially in the most recent times. The increase in distance-learning educational programs in universities has increased the opportunities for student learning and self-development together with virtual reality applications, and the implementation of web-based projects and lessons. However, this system has caused university students to spend longer at a computer. Intense mental activity and long sedentary periods can result in individuals feeling more tired and stressed [14].

Raising awareness of the musculoskeletal system problems that can develop associated with the use of technological devices is important in respect of protective healthcare. Previous studies have examined the effects of a sitting posture on the neck and upper extremity musculoskeletal system symptoms [8-10]. However, not many studies have been conducted which have examined the usage time of devices by students and the effects on head and neck posture when sitting while using devices. 
The hypothesis of this study was that posture, stretching and strengthening exercises applied actively during the day would have a positive effect on sleep quality, the severity level of tiredness, neck problems and head posture of university students. Therefore, the aim of this study was to examine the effect of an exercise program on the sleep quality, fatigue, neck problems and posture of university students and to increase the cognitive awareness of students of head posture when using a computer or smartphone, the time spent sitting daily and the number of steps taken per day.

\section{Material and Methods}

This study was conducted on 54 university students between October and December 2019 to investigate the effects of a 5 x 5 exercise protocol on sleep quality, fatigue and neck problems. The effects of the exercise program were also investigated on the time spent sitting each day, the number of steps taken each day, the duration of sleep, and the duration of smartphone usage. The study was conducted by physiotherapists (AUTHORS) in the Physiotherapy and Rehabilitation Department of a health sciences faculty.

Approval for the study was granted by the NonInterventional Clinical Research Ethics Committee of AUTHORS' University (No: 2019/27). All procedures were applied in compliance with the principles of the Helsinki Declaration.

Participants. The study enrolled 81 volunteer university students selected from the Physiotherapy and Rehabilitation Department students (49 females - 66.7\%; 32 males $-36.4 \%$ ). The study inclusion criteria were defined as age 19-30 years, voluntary participation in the study, no chronic physical disease, and smartphone use for at least 1 hour per day for at least 3 years. Students were excluded from the study if they had a history of a musculoskeletal system problem that had lasted at least 1 week in the previous 6 months, a history of surgery in the neck region or upper extremities, or if they had any cardiopulmonary problem. A total of 54 university students met the criteria, comprising $37(68 \%)$ females and $17(32 \%)$ males. The content of the $5 \times 5$ exercise protocol was explained and informed consent for participation in the study was obtained from all the participants.

Procedure. The descriptive data of the students was collected on a Sociodemographic Information Form prepared by the researchers. Age, gender, height, weight and general health information was obtained. From the pedometer application on the smartphone of each student the weekly number of steps taken was recorded and the daily average was calculated. The daily time spent sitting, daily usage time of the smartphone and daily duration of sleep were determined from the physical activity application on the smartphone.

The Forward Head Position (FHP) of each student was evaluated with the craniovertebral angle. The student was instructed to sit upright on a chair in a neutral posture, then the craniovertebral angle was calculated as the angle formed from the plane passing from the 7 th cervical vertebra to the tragus of the ear horizontally parallel to the ground. Subjects with FHP were determined to have a smaller craniovertebral angle than healthy subjects. This angle has been reported to be a valid and reliable evaluation tool for the evaluation of FHP [15]. To determine the sleep quality of the students, the Pittsburgh Sleep Quality Index (PSQI) was used, for neck problems, the Neck Disability Index (NDI), and for the level of fatigue, the Fatigue Severity Scale (FSS).

Pittsburgh Sleep Quality Index (PSQI); The PSQI provides information about sleep quality in the last month, and the type and severity of sleep disorders [16].The scale consists of 24 items in 7 components of subjective sleep quality, sleep latency, sleep duration, sleep efficiency, sleep disturbance, use of sleep medication, and daytime dysfunction. The total of the 7 component scores provides the total PSQI score. Each component has a total score of $0-3$, so the total PSQI score ranges from 0-21. A total score of $>5$ indicates poor sleep quality. The Turkish version of the scale used in the study has been validated [17].

Fatigue Severity Scale (FSS); The scale consists of 9 items with a total score ranging from $9-63$. A score of $\geq 36$ indicates severe fatigue. The subject indicates their level of agreement with each of the items on a scale of $1-7$, where $1=\mathrm{I}$ completely disagree and $7=\mathrm{I}$ completely agree. The total score is calculated as the average of the 9 item scores. A cut off value of $\geq 4$ has been defined for pathological fatigue. The lower the total score, the lower the level of fatigue [18]. The Turkish version of the scale was used with a Cronbach alpha coefficient of 0.96 [19].

Neck Disability Index (NDI); The NDI consists of 10 sections related to the severity of pain, personal care, lifting loads, reading, headache, concentration, work, driving, sleep and leisure activities. Each item is scored from 0-5. A total score of 0-4 points indicates no disability, 5-14 points, mild disability, 15-24 points, moderate disability, 25-34 points, severe disability and $>35$ points, complete disability [20]. The validated Turkish version of the scale was used in the study [21].

The evaluation scales were applied to the 54 students who voluntarily agreed to participate in the study before the exercises were given. The exercises were then explained in detail to the students. The $5 \times 5$ exercise program consisted of 5 exercises, as shown in Table 1, to be performed 5 times a day, 5 days a week for 5 weeks. A form was prepared for the students to record the days and times of completing the exercises. A brochure detailing the exercises was also given to the students, who were then evaluated again after 5 weeks.

Statistical Analysis

Data obtained in the study were analysed statistically using IBM ${ }^{\circledR}$ SPSS $\odot 21.0$ software (SPSS Inc., Chicago, IL, USA). The conformity of the variables to normal distribution was examined using visual (histogram and probability graphs) and analytical methods (ShapiroWilks test). Descriptive data were expressed as mean \pm standard deviation $(\mathrm{X} \pm \mathrm{SD})$, and minimum-maximum values. The Paired Samples t-test was used to compare the difference between pre-exercise and post-exercise 
variables. Statistical significance level was accepted as $\mathrm{p}$ $<0.05$.

\section{Results}

Evaluation was made of a total of 54 students comprising 37 females and 17 males with a mean age of $22.50 \pm 1.87$ years, and mean BMI of $22.28 \pm 3.45 \mathrm{~kg} / \mathrm{m}^{2}$ (Table 2). The pre and post exercise values of the students for PSQI, FSS, NDI, and FHP are shown in Table 3. A significant change was determined in the PSQI, FSS and
NDI values following the $5 \times 5$ exercise program $(\mathrm{p}<0.05)$. No change was determined in the FHP compared to baseline data $(\mathrm{p}>0.05)$. The number of steps taken per day, the time spent sitting (hrs), the duration of sleep (hrs) and duration of smartphone usage (hrs) before and after the exercise program are shown in Table 4. No significant difference was determined in the daily number of steps, or time spent sitting, sleeping or using a phone or computer after the exercise program compared to the baseline data $(\mathrm{p}>0.05)$.

Table 1. The $5 \times 5$ Exercise Program

Exercise

Diaphragmatic Breathing

Axial extension of the neck

(Chin tuck)

Cervical Stabilization

(Craniocervical flexion)

Pectoral Stretching

Shoulder /Scapular Retraction Strengthening

\section{Instruction}

While seated, place one hand the upper chest and the other hand below the rib cage. Deep abdominal breathing in and out through the nose so that stomach moves out against the hand. Holding the breath $10 \mathrm{sec}$. and breathing out. The hand on the upper chest should remain as still as possible. Repeat 10 times.

While seated, pull the chin and head straight back until a good stretch is felt at the base of the head and top of the neck. Hold for 10 seconds, relax and bring the chin forward. Repeat 10 times.

Lying supine, perform a nodding movement without lifting the head off the bed and push the head gently back to the surface, feeling the back of the head sliding in the sagittal plane. Hold for 10 seconds, relax and bring the head back to beginning position. Repeat 10 times.

Standing in an open doorway or corner with both hands slightly above your head on the door frame or wall. Slowly lean forward until you feel a stretch in the front of your shoulders. Hold for 10 seconds.

Standing or sitting, pull the shoulder blades together and downwards and hold for 10 seconds, relax.

Table 2. Descriptive data of the students

\begin{tabular}{lll}
\hline Characteristics & X \pm SD & min-max \\
\hline Age (years) & $22.50 \pm 1.87$ & $19-30$ \\
BMI $\left(\mathrm{kg} / \mathrm{m}^{2}\right)$ & $22.28 \pm 3.45$ & $17-30$ \\
Female N (\%) & $37(68)$ & \\
Male N (\%) & $17(32)$ & \\
\hline
\end{tabular}

Note: BMI: Body Mass Index; X: Mean, SD: Standard Deviation

Table 3. The comparison of sleep quality, fatigue severity, neck disability, and head posture values pre and post exercise program

\begin{tabular}{lllll}
\hline $\begin{array}{l}\text { Scales } \\
\text { (min-max) }\end{array}$ & Pre-exercise & Post- exercise & $\mathbf{t}$ & $\mathbf{p}$ \\
\hline PSQI (0-21) & $\mathbf{X} \pm$ SD & $\mathbf{X} \pm$ SD & & $\mathbf{0 . 0 0 2 *}$ \\
FSS (1-7) & $7.13 \pm 3.34$ & $5.55 \pm 2.86$ & 3.296 & $\mathbf{0 . 0 0 0 *}$ \\
NDI (0-50) & $4.64 \pm 1.25$ & $3.78 \pm 1.60$ & 4.053 & $\mathbf{0 . 0 0 3 *}$ \\
FHP () & $10.78 \pm 6.91$ & $8.65 \pm 5.73$ & 3.122 & 0.076 \\
\hline
\end{tabular}

NOTE: ${ }^{*}$ <<0.05; PSQI: Pittsburgh Sleep Quality Index; FSS: Fatigue Severity Scale; NDI: Neck Disability Index; 
Table 4. The comparison of the assessments before and after the $5 \times 5$ exercise program

\begin{tabular}{|c|c|c|c|c|}
\hline Assessments & $\begin{array}{l}\text { Pre-exercise } \\
\mathrm{X} \pm \mathrm{SD}\end{array}$ & $\begin{array}{l}\text { Post- exercise } \\
\mathrm{X} \pm \text { SD }\end{array}$ & $\mathbf{t}$ & $\mathbf{p}$ \\
\hline Steps (number/daily) & $5715.56 \pm 2512.05$ & $6543.64 \pm 2477.19$ & 1.91 & 0.062 \\
\hline Sitting time (hour/daily) & $5.26 \pm 1.98$ & $5.40 \pm 2.35$ & 0.508 & 0.614 \\
\hline Sleep time (hours/night) & $7.48 \pm 1.22$ & $7.42 \pm 1.20$ & 0.401 & 0.690 \\
\hline Smartphone use time (minutes/daily) & $218 \pm 148$ & $221 \pm 135$ & 0.182 & 0.857 \\
\hline
\end{tabular}

NOTE: ${ }^{*} p<0.05 ;$ X: Mean, SD: Standard Deviation

\section{Discussion}

The aim of this study was to examine the effect of a 5 x 5 exercise program on the sleep quality, neck disability, fatigue, head posture, number of daily steps, hours of sleep, time spent sitting and the duration of smartphone usage of university students. At the end of the 5-week exercise program, there was determined to be a statistically significant increase in sleep quality, and a statistically significant decrease in the levels of fatigue and neck dysfunctions. No significant change was seen in the head posture angular value, number of daily steps or time spent sitting, sleeping, or using the smartphone.

Addiction to technological devices is seen to increase in university students for reasons such as the change in surroundings, intense academic life, examinations, messaging and following social media $[3,5]$. Going to bed late, insomnia and impaired sleep quality emerge in individuals associated with addiction to technological devices $[12,13]$. With good sleep quality, an individual is refreshed in the morning and feels physically and mentally ready for a new day. However, poor quality and insufficient sleep is associated with low cognitive performance in the long term, slowing of the metabolism and weight problems, and an increased cardiovascular risk develops [5-7]. Studies that have examined the sleep quality of university students have determined that more than half have poor quality sleep [22-24]. It has been emphasised in literature that young people aged 19-29 years do not have sufficient sleep and therefore experience more physical, psychosocial and health problems [12]. Demirci et al [25] found that sleep quality, depression, and anxiety may be associated with Smartphone overuse. It has also been reported that there is a strong association between sleep quality and physical and mental status, and those with poor sleep experience problems such as daytime fatigue, and sleepiness, stress and depression $[24,25]$. One of the first evident symptoms of poor quality and insufficient sleep is daytime tiredness [26]. In the current study, the sleep quality of the students was seen to be at an extremely low level at the beginning of the study. A PSQI score of $\geq 5$ is accepted as poor sleep quality. Despite a statistically significant increase in the sleep quality of the students after the 5-week exercise program, the mean PSQI score was determined as $>5$. Nevertheless, the improvement in the sleep quality after the exercise program had a positive effect on the level of fatigue, which decreased. Thus, it can be concluded that 15-20 mins of exercises applied during the day is effective on sleep quality and fatigue and could decrease serious problems in the long term.

Increased accessibility to information due to technological developments has made life easier for people and has increased the use of technological devices. However, while the long-term use of these devices consciously or subconsciously has a negative effect on all age groups, it is seen to be the greatest risk factor for the young age group [2, 3]. Technology addiction has been determined in this age group with inactivity, sitting in the same position for a long period and poor head posture $[6,27]$. In this study which aimed to raise awareness in students, although the 5-week period of exercises repeated at certain intervals was not determined to have created a change in head posture, there was a significant reduction in the neck disability values of the students. Although the students in this study were healthy individuals with no neck pain or other complaints, there were deviations in head posture. The results obtained by Lee et al. [27] support these findings. They reported that cervical angles showed increased flexion in asymptomatic subjects during visual display terminal work. Head and neck posture deviation seen in individuals without a neck problem can be explained by the changing motor control of the neck muscles associated with incorrect postural habits [28].

In the frequent observation of neck problems, there has been said to be a direct biomechanical relationship between the head and cervical region [29]. Many people may use smartphones with the head shifted forward and the smartphone placed near the waist or lap while in a sitting position, maintaining a static sitting posture during smartphone use. This flexed neck posture can increase the movement of the cervical spine and may induce muscle strain in adjacent portions of the cervical spine [9, 30]. A smaller craniovertebral angle, in other words, FHP, which is frequently seen in office workers and those who are seated for long periods, is a syndrome which can emerge 
with abnormal posture in the shoulder girdle [31]. Loss of motor control involves failure to control joints, because of lack of coordination of the agonist-antagonist muscle co-activation [29].

Head posture and balance of the neck muscles are important for postural stability and functionality before musculoskeletal system problems develop. With a combined program including stretching, strengthening and behavioural active control for the correction of postural deviations, Lee et al [32]. obtained significant results in patients with neck and thoracic region problems. Kendall recommended strengthening of weakened postural muscles and stretching of shortened muscles for a balanced posture [33]. In the context of an exercise program to be given with the principles of stretching and strengthening for FHP, soft tissue balance can be obtained with strengthening of the deep cervical flexors and shoulder retractors, and stretching of the pectoral muscles [32-34]. In a study by Han et al, decreased activity of accessory respiratory muscle activity was determined in subjects with FHP compared to subjects without FHP [35]. In the current study exercise program, the students were instructed to breathe diaphragmatically in a controlled manner without disrupting the correct head posture and to concentrate on their breathing. It has been reported that diaphragmatic breathing exercises provide a reduction in blood pressure and pulse rate by stimulating the parasympathetic system, lower the stress level of the individual and create a sedative effect [36]. In a study of Canadian university students, the duration and frequency of use of mobile handheld devices was found to be related to the prevalence of neck pain [37]. Kim et al. investigated the effect of the duration of smartphone use on neck and shoulder muscle fatigue and pain in adults with FHP. The cervical flexion angles were affected by the duration of smartphone use, with pain and fatigue observed to worsen with longer periods of use. Correct posture and break time of at least 20 minutes were recommended when using smartphones [10]. In the current study, the students were instructed to repeat the exercises 5 times during the day. It was aimed for the students to be active during the day by eliminating the inactivity and static posture formed by a long period of sitting. It can be considered that the ability to adjust the correct sitting posture, the time spent sitting and the time spent using technological devices of young people and to create habits of these will make a positive contribution to their general health.
It has been reported that individuals with neck problems have a greater tendency to make adaptations in the head and neck, and a significant relationship has been found between FHP and neck pain [31, 38]. In a study that compared patients with severe chronic neck pain with subjects with no neck pain, those with chronic pain were found to have a reduced ability to maintain an upright neutral posture at a computer [31]. Reasons for chronic pain can include altered muscle length relationships, postural changes, muscular imbalances, and variations in location of the centres of mass and of pressure [39]. Therefore, the most effective and cheapest method is to take precautions before the problems develop. In the current study it was aimed to move the healthy students from the same long-term static position, even if for a short time, with the application of exercises 5 times a day. With the gaining of habits of an aware use of technological devices, protection of correct head and neck posture during use, reduction in the time spent using devices, and increasing daily physical activity levels, it is possible to say that university students could reduce the risk of primarily, pain in the neck region and the development of musculoskeletal system problems in other regions.

There were some limitations to this study, primarily the small sample size as only healthy young adults were included. Further studies could make comparisons with subjects with neck pain. As the study group was a homogenous group of healthy university students, it is not possible to generalize the findings to the whole population. In addition, the study was limited to a 5-week exercise program. There is a need for further studies of a longer duration to examine the effect of the exercise program and to make comparisons with a control group.

\section{Conclusion}

The results of this study demonstrated that the $5 \times 5$ exercise program administered to university students increased sleep quality, and decreased neck disability and fatigue levels. The $5 \times 5$ exercise program, which focused on posture and stability of the head and neck region of the spine, can be used for postural pain and misalignment of the spine, problems related to forward head posture, and neck disorders.

\section{Conflict of interests}

The authors have no conflict of interests to declare. 


\section{References}

1. Bisen SS, Deshpande YM. Understanding internet addiction: a comprehensive review. Mental Health Review, Journal. 2018; 23(3): 165-184. https://doi.org/10.1108/MHRJ-07-2017-0023

2. Kuss DJ, Griffiths MD. Online Social Networking and Addiction- A Review of the Psychological Literature. Int $J$ Environ Res Public Health. 2011;8(9):3528-3552. https://doi.org/10.3390/ijerph8093528

3. Ben-Yehuda L, Greenberg L, Weinstein A. Internet Addiction by Using the Smartphone-Relationships between Internet Addiction, Frequency of Smartphone Use and the State of Mind of Male and Female Students. $J$ Reward Defic Syndr Addict Sci. 2016; 2(1): 22-27. https://doi.org/10.17756/jrdsas.2016-024

4. Lee YS. Biological Model and Pharmacotherapy in Internet Addiction. J Korean Med Assoc. 2006;49(3):209-214. https://doi.org/10.5124/jkma.2006.49.3.209

5. De-Sola Gutiérrez J, Rodríguez de Fonseca F, Rubio G. CellPhone Addiction: A Review. Front Psychiatry. 2016;7:175. https://doi.org/10.3389/fpsyt.2016.00175

6. Peterson NE, Sirard JR, Kulbok PA, DeBoer MD, Erickson JM. Sedentary behavior and physical activity of young adult university students. Research in nursing \& health. 2018; 41(1): 30-38. https://doi.org/10.1002/nur.21845

7. Sahin M, Lok S. Relationship between physical activity levels and internet addiction of adults. JDepress Anxiety. 2018;7:310. https://doi.org/10.4172/2167-1044.1000310

8. Kim HJ; DH, Kim JS. The relationship between smartphone use and subjective musculoskeletal symptoms and university students. J Phys Ther Sci. 2015;27(3):575-579. https://doi.org/10.1589/jpts.27.575

9. Park J, Kim J, Kim J, Kim K, Kim N, Choi I, et.al. The effects of heavy smartphone use on the cervical angle, pain threshold of neck muscles and depression. Advanced Science and Technology Letters. 2015;91:12-7. https://doi.org/10.14257/ASTL.2015.91.03

10.Kim MS. Influence of neck pain on cervical movement in the sagittal plane during smartphone use. $J$ Phys Ther Sci. 2015;27(1):15-17. https://doi.org/10.1589/jpts.27.15

11.Yip CH, Chiu TT, Poon AT. The relationship between head posture and severity and disability of patients with neck pain. Man Ther. 2008;13(2):148-154. https://doi.org/10.1016/j.math.2006.11.002

12.Orzech KM, Salafsky DB, Hamilton LA. The state of sleep among college students at a large public university. $J$ Am Coll Health. 2011;59(7):612-619. https://doi.org/10.1080/07448481.2010.520051

13.Moattari M, Moattari F, Kaka G, Kouchesfahani HM, Sadraie SH, Naghdi M. Smartphone Addiction, Sleep Quality and Mechanism. Int J Cogn Behav. 2017; 1:002. https://doi.org/10.23937/IJCB-2017/1710002

14.Augner C, Hacker GW. Associations between problematic mobile phone use and psychological parameters in young adults. Int $J$ Public Health. 2012;57(2):437-441. https://doi.org/10.1007/s00038-011-0234-z

15.Shaghayegh Fard B, Ahmadi A, Maroufi N, Sarrafzadeh J. Evaluation of forward head posture in sitting and standing positions. Eur Spine J. 2016;25(11):3577-3582. https://doi.org/10.1007/s00586-015-4254-x

16.Buysse DJ, Reynolds CF 3rd, Monk TH, Berman SR, Kupfer DJ. The Pittsburgh Sleep Quality Index: a new instrument for psychiatric practice and research. Psychiatry Res. 1989;28(2):193-213. https://doi.org/10.1016/0165-1781(89)90047-4

17.Ağargün MY, Kara H, Anlar O. Validity and reliability of Pittsburgh Sleep Quality Index. Turkish Journal of Psychiatry. 1996;7:107-115. (In Turkish).

18.Krupp LB, LaRocca NG, Muir-Nash J, Steinberg AD. The fatigue severity scale. Application to patients with multiple sclerosis and systemic lupus erythematosus. Arch Neurol. 1989;46(10):1121-1123. https://doi.org/10.1001/archneur.1989.00520460115022

19. Armutlu K, Cetisli Korkmaz N, Keser I, Sumbuloglu $\mathrm{V}$, Irem Akbiyik $\mathrm{D}$, Guney $\mathrm{Z}$, et al. The validity and reliability of the Fatigue Severity Scale in Turkish multiple sclerosis patients: International Journal of Rehabilitation Research, 2007;30:81-5. https://doi.org/10.1097/MRR.0b013e3280146ec4

20.Vernon H, Mior S. The Neck Disability Index: a study of reliability and validity [published correction appears in J Manipulative Physiol Ther 1992 Jan;15(1):followi]. $J$ Manipulative Physiol Ther. 1991;14(7):409-415. https://doi.org/10.1037/t35122-000

21.Aslan E, Karaduman A, Yakut Y, Aras B, Simsek İE, Yaglý N. The Cultural Adaptation, Reliability and Validity of Neck Disability Index in Patients With Neck Pain: A Turkish Version Study. Spine, 2008;33:E362-5. https://doi.org/10.1097/BRS.0b013e31817144e1

22.Li L, Wang YY, Wang SB, et al. Sleep Duration and Sleep Patterns in Chinese University Students: A Comprehensive Meta-Analysis. J Clin Sleep Med. 2017;13(10):1153-1162. https://doi.org/10.5664/jcsm.6760

23.Levenson JC, Shensa A, Sidani JE, Colditz JB, Primack BA. The association between social media use and sleep disturbance among young adults. Prev Med. 2016;85:36-41. https://doi.org/10.1016/j.ypmed.2016.01.001

24.Keshavarz Akhlagh A, Ghalebandi M F. Sleep Quality and Its Correlation with General Health in Pre-university Students of Karaj, Iran. Iran J Psychiatry Behav Sci. 2009; 3(1):44-9.

25.DemirciK,Akgönül M,AkpınarA. Relationship of smartphone use severity with sleep quality, depression, and anxiety in university students. J Behav Addict. 2015;4 (2): 85-92. https://doi.org/10.1556/2006.4.2015.01

26.Jenaro C, Flores N, Gomez-Vela M, GonzalezGil F, Caballo C. Problematic Internet and cellphone use: psychological, behavioral and health correlates. Addict Res Theory. 2007;15(3):309-20. https://doi.org/10.1080/16066350701350247

27.Lee JH, Park SY, Yoo WG. Changes in craniocervical and trunk flexion angles and gluteal pressure during VDT work with continuous cross-legged sitting. $J$ Occup Health. 2011;53(5):350-355. https://doi.org/10.1539/joh.11-0050-oa

28.Harrison DD, Harrison SO, Croft AC, Harrison DE, Troyanovich SJ. Sitting biomechanics part I: review of the literature. J Manipulative Physiol Ther. 1999;22(9):594-609. https://doi.org/10.1016/s0161-4754(99)70020-5

29. Armijo Olivo S, Magee DJ, Parfitt M, Major P, Thie NM. The association between the cervical spine, the stomatognathic system, and craniofacial pain: a critical review. J Orofac Pain. 2006;20(4):271-287.

30.Bababekova Y, Rosenfield M, Hue JE, Huang RR. Font size and viewing distance of handheld smart phones. Optom Vis Sci. 2011;88(7):795-797. https://doi.org/10.1097/OPX.0b013e3182198792

31.Szeto GP, Straker LM, O'Sullivan PB. A comparison of symptomatic and asymptomatic office workers 
performing monotonous keyboard work-2: neck and shoulder kinematics. Man Ther. 2005;10(4):281-291. https://doi.org/10.1016/j.math.2005.01.005

32.Lee NK, Jung SI, Lee DY, Kang KW. Effects of Exercise on Cervical Angle and Respiratory Function in Smartphone Users. Osong Public Health Res Perspect. 2017;8(4):271-274. https://doi.org/10.24171/j.phrp.2017.8.4.07

33.Kendall F, Kendall McCreary E, Provance P, Rodgers PP, Romani WA. Muscles: Testing and Function with Posture and Pain. $5^{\text {th }}$ ed. Baltimore. MD: Williams \& Wilkins; 2005.

34.Park SK, Yang DJ, Kim JH, Kang DH, Park SH, Yoon JH. Effects of cervical stretching and craniocervical flexion exercises on cervical muscle characteristics and posture of patients with cervicogenic headache. $J$ Phys Ther Sci. 2017;29(10):1836-1840. https://doi.org/10.1589/jpts.29.1836

35.Han J, Park S, Kim Y, Choi Y, Lyu H. Effects of forward head posture on forced vital capacity and respiratory muscles activity. $J$ Phys Ther Sci. 2016;28(1):128-131. https://doi.org/10.1589/jpts.28.128
36.Varvogli L, Darviri C. Stress management techniques: evidence-based procedures that reduce stress and promote health. Health Science Journal. 2011;5(2): 74-89.

37.Berolo S, Wells RP, Amick BC 3rd. Musculoskeletal symptoms among mobile hand-held device users and their relationship to device use: A preliminary study in a Canadian university population. Appl Ergon. 2011;42(2):371-378. https://doi.org/10.1016/j.apergo.2010.08.010

38. Mahmoud NF, Hassan KA, Abdelmajeed SF, Moustafa IM, Silva AG. The Relationship Between Forward Head Posture and Neck Pain: a Systematic Review and Meta-Analysis. Curr Rev Musculoskelet Med. 2019;12(4):562-577. https://doi.org/10.1007/s12178-019-09594-y

39.Panjabi MM. The stabilizing system of the spine. Part I. Function, dysfunction, adaptation, and enhancement. J Spinal Disord. 1992;5(4):383-397. https://doi.org/10.1097/00002517-199212000-00001

\section{Information about the authors:}

Aysenur Tuncer; (Corresponding Author); https://orcid.org/0000-0002-5660-1134; aysenur.tuncer@hku.edu.tr; Faculty of Health Sciences, Department of Physiotherapy and Rehabilitation, Hasan Kalyoncu University; Gaziantep, Turkey.

Tuba Maden; Research asisstant; https://orcid.org/0000-0001-8713-0825; tuba.kaplan@hku.edu.tr; Department of Physiotherapy and Rehabilitation, Hasan Kalyoncu University; Gaziantep, Turkey.

Tugba Badat; Research asisstant; https://orcid.org/0000-0002-0484-0221; tugba.badat@hku.edu.tr; Department of Physiotherapy and Rehabilitation, Hasan Kalyoncu University; Gaziantep, Turkey.

Deniz Kocamaz; https://orcid.org/0000-0002-0611-7686; deniz.erdankocamaz@hku.edu.tr; Faculty of Health Sciences, Department of Physiotherapy and Rehabilitation, Hasan Kalyoncu University; Gaziantep, Turkey.

\section{Cite this article as:}

Tuncer A, Maden T, Badat T, Kocamaz D. The effects of $5 \times 5$ exercises on a quality of life of university students, who use smartphones during long periods. Physical Education of Students, 2020;24(5):271-277. https://doi.org/10.15561/20755279.2020.0503

This is an Open Access article distributed under the terms of the Creative Commons Attribution License, which permits unrestricted use, distribution, and reproduction in any medium, provided the original work is properly cited http://creativecommons.org/licenses/by/4.0/deed.en

Received: 25.08 .2020

Accepted: 02.10.2020; Published: 30.10.2020 